\title{
A INVESTIGAÇÃO COMO POSSIBILIDADE DO INÉDITO: RECORTES DE PRÁTICAS DOCENTE NA EDUCAÇÃO INFANTIL
}

\author{
Mateus Lorenzon ${ }^{1}$ \\ Jacqueline Silva da Silva ${ }^{2}$
}

\begin{abstract}
Resumo: Neste artigo, apresentam-se recortes de práticas investigativas realizadas junto a crianças da Educação Infantil, analisando a interface existente entre a investigação e demais princípios do planejamento pedagógico. O estudo aproxima-se de uma pesquisa-ação, em que as situaçóes vivenciadas são confrontadas com pressupostos teóricos e analisadas a partir de uma abordagem molar. O corpus de pesquisa foi elaborado por meio de um critério de conveniência, no qual selecionaramse episódios de práticas pedagógicas desenvolvidas no período de 2019-2021 e registradas na Documentação Pedagógica. Os registros foram dispostos em três categorias, nas quais são abordadas, respectivamente, as investigaçóes cotidianas, investigaçôes exploratórias e investigaçóes projetadas. Observa-se que o desenvolvimento de práticas investigativas requer a modificação de tempos, espaços e materiais que são destinados ao acolhimento das crianças. Por fim, destaca-se que práticas investigativas seguem os princípios de particularidade e extensibilidade, isto é, ocorrem em um contexto específico e são condicionados por elementos contidos na organização escolar. No entanto, elas podem ser extensíveis, apresentando elementos comuns e que podem servir como estímulo para novas práticas.
\end{abstract}

Palavras chave: Investigação. Educação Infantil. Prática Pedagógica.

\section{RESEARCH AS A POSSIBILITY OF THE UNPRECEDENTED: SCRIPTS OF TEACHING PRACTICES IN EARLY CHILDHOOD EDUCATION}

Abstract: This article presents clippings of investigative practices carried out with children in Early Childhood Education, analyzing the existing interface between research and other principles

1 Graduado em Pedagogia - UNIVATES. Mestre em Ensino - UNIVATES. Professor das Redes Públicas de Ensino de Arroio do Meio - RS e Lajeado - RS.

2 Doutora em Educação - UFRGS. Professora titular da UNIVATES, atuando nos cursos de Pedagogia, no Programa de Pós Graduação em Ensino e no Programa de Pós Graduação em Ensino de Ciências Exatas. 
of pedagogical planning. The study comes close to an action research, in which it narrates situations experienced, confronting them with theoretical assumptions and analyzing them with a molar approach. The research corpus was prepared using a convenience criterion, in which episodes of pedagogical practices developed in the period 2019-2021 were selected and recorded in the Pedagogical Documentation. The records were arranged in three categories, in which daily investigations, exploratory investigations and information investigations are addressed. It is observed that the development of investigative practices requires the modification of the times, spaces and materials that are intended for the reception of children. Finally, it is highlighted that investigative practices follow the principles of particularity and extensibility, that is, they occur in a specific context and are conditioned by elements contained in the school organization. However, they can be extensible, with common elements that can serve as a stimulus for new practices.

Keywords: Pedagogical Practice. Investigation. Child education.

\section{Introduçáo}

A educação está inevitavelmente relacionada com os tempos históricos e os espaços geográficos em que ocorre, sendo influenciada pelas transformaçóes culturais, sociais, políticas e econômicas ocorridas na sociedade (HOYUELOS, 2020). Dahlberg, Moss e Pence (2019) corroboram com essa perspectiva, afirmando que as instituiçôes de educação voltadas à primeira infância são construçôes sociais e que a comunidade em torno dela é que define seus propósitos e objetivos. Logo, a escola de Educação Infantil não possui uma essência transcendente e imutável, mas é "filha do tempo atual" (HOYUELOS, 2020. p. 49). Esse entendimento de uma instituição escolar conectada estruturalmente ao meio em que está inserida, longe de resultar em uma perspectiva determinística, responsabiliza seus agentes humanos (crianças, professores, familiares, funcionários) pela sua construção.

Dessa forma, como educadores, estamos incumbidos de uma tarefa que demanda escolhas éticas e políticas, bem como clareza sobre os conceitos subjacentes em nossas práticas pedagógicas. Ao abordar essas discussóes, no âmbito da Educação Infantil, é imprescindível pensar em práticas pedagógicas e contextos desenvolvimentais que contemplem as múltiplas dimensóes necessárias para a constituição do sujeito-criança. Assim, o objetivo precípuo para o trabalho nesta etapa de ensino deixa de ser os aspectos cognitivos e passa a ser as cem linguagens constituintes da infância (ROCHA, 2001; MALAGUZZI, 2016).

$\mathrm{O}$ atendimento às crianças de 0 a 5 anos em instituiçôes educacionais, segundo Rocha (2001), exige identificar as especificidades das práticas pedagógicas destinadas a este público. $\mathrm{O}$ reconhecimento da infância, não como uma categoria universal e abstrata, mas sim como uma construçáo cultural e geracional, leva ao reconhecimento da criança como um sujeito que tem direito a participar e a ser escutada (ROCHA, LESSA, BUSS-SIMÁO, 2016; CARVALHO, FOCHI, 2016). Essa visão, contemplada nas Diretrizes Curriculares Nacionais da Educação Infantil (BRASIL, 2009), tensiona a organização dos currículos das escolas por se contrapor às tendências escolarizantes e assistenciais destinadas à primeira infância. 
Nesse viés, reafirmar a suposição da criança como um sujeito de direitos implica pensar a Educaçáo Infantil como uma etapa que tenha como objetivo ampliar as experiências de mundo das crianças, permitindo a elas o desenvolvimento e a consolidaçáo de novas aprendizagens (BRASIL, 2018). No entanto, as Diretrizes Curriculares Nacionais para a Educação Infantil (BRASIL, 2009) e a Base Nacional Comum Curricular (BRASIL, 2018) salientam que, para atingir esse objetivo, é necessário desenvolver propostas curriculares organizadas em torno de dois eixos norteadores: as interaçôes e as brincadeiras.

Dadas as especificidades das infâncias, as pedagogias voltadas a elas devem assumir um caráter holístico e ecológico, adotando um princípio epistemológico que respeite a complexidade e a concepção de instituição educativa como algo contextualizado (FORMOSINHO, OLIVEIRA-FORMOSINHO. 2019). Em decorrência disso, quando se fala em Práticas Investigativas na Educação Infantil, é fundamental pensar em uma abordagem distinta daqueles autores que tratam do Ensino por Investigação ou Educar pela Pesquisa por um viés estritamente propedêutico. A Investigação, no contexto da escola infantil, tem uma ênfase processual e está voltada ao desenvolvimento integral e multidimensional das crianças.

Frente ao exposto, reiteramos que o objetivo deste estudo é apresentar recortes de práticas investigativas realizadas junto a crianças da Educação Infantil, analisando a interface existente entre a investigação e os demais princípios do planejamento pedagógico. Os pressupostos teóricos deste estudo são constituídos por autores que abordam as Pedagogia(s) da Infância (ROCHA, 2001; CARVALHO, FOCHI, 2016; ROCHA, LESSA, BUSS-SIMÁO, 2016; FORMOSINHO, OLIVEIRAFORMOSINHO, 2019) e o Planejamento na Abordagem Emergente (SILVA, 2011; RINALDI, 2016; MALAGUZZI, 2016; HOYUELOS, RIERA, 2019; HOYUELOS, 2020).

\section{A Investigaçáo como um desdobramento das Pedagogia(s) da Infância}

Nesta seção do artigo, discutimos as Práticas Investigativas como uma derivação das Pedagogia(s) da Infância. Sendo assim, as referidas práticas são entendidas aqui como um âmbito específico da Pedagogia. Rocha (2001) e Rocha, Lessa e Buss-Simão (2016) afirmam que a defesa de uma Pedagogia da Infância foi resultado de um conjunto de estudos que tratavam da educação das crianças pequenas, indicando uma preocupação acerca da necessidade de os processos educativos voltados a este público serem dotados de especificidades. Assim, urgia a necessidade de pensar uma pedagogia que se distingisse das perspectivas modernas, até então hegemônicas e assentadas sobre uma compreensão de criança como uma categoria universal e essencializada (COUTINHO, ROCHA, 2007; DAHLBERG, MOSS, PENCE, 2019).

Subjacente a esta pedagogia, encontra-se uma imagem de infância decorrente de estudos sociológicos e antropológicos que a apresentavam como uma categoria social, cultural e geracional, náo podendo ser pensada como algo universal e 
essencializado (COHN, 2005; CORSARO, 2015). Esse princípio, fundante da Pedagogia da Infância vigente na Educação Infantil e no Ensino Fundamental no decorrer da modernidade, indicava a necessidade de pensar uma escola que tencionasse as perspectivas escolarizantes e/ou a suposição de que a escola era, unicamente, um instrumento social voltado a práticas assistenciais.

Assim, contrastando as pedagogias transmissivas ${ }^{3}$, surge uma Pedagogia da Infância que prioriza um âmbito relacional, na qual as crianças são compreendidas como atores sociais, sujeitos de direitos e detentoras de vozes e opiniốes próprias “[...] que devem ser ouvidas de modo a serem consideradas com seriedade, envolvendo-as no diálogo e na tomada de decisões democráticos" (DAHLBERG, MOSS, PENCE, 2019, p. 71). Em decorrência disso, os currículos para a primeira infância passam a ser pensados náo como uma lista previamente elaborada de conteúdos, ou como um organograma de habilidades, mas sim como uma projetação, planejada de modo colaborativo.

Tais pressuposições são contempladas nas Diretrizes Curriculares Nacionais para Educação Infantil - DCNEI (BRASIL, 2009) e na Base Nacional Comum Curricular - BNCC (BRASIL, 2018). O primeiro documento, que apresenta caráter orientador, afirma que, ao contemplar a criança como sujeito do planejamento curricular, é necessário pensar em práticas que estruturam o cotidiano:

Intencionalmente planejadas e permanentemente avaliadas [...] [devendo] considerar a integralidade e indivisibilidade das dimensóes expressivomotoras, afetiva, cognitiva, linguística, ética, estética e sociocultural, apontar as experiências de aprendizagem que se espera promover junto às crianças (BRASIL, 2009, p. 6).

A partir dessa afirmação, vislumbramos que as organizaçóes curriculares decorrentes náo são entregues ao acaso ou baseadas na improvisação, mas sim contemplam as incertezas, os acontecimentos do cotidiano e são baseadas na escuta (MALAGUZZI, 2016). Sob tal ângulo, o professor renuncia ao caráter de guia ou ensinador, assumindo o "papel ativo de promover experiências de aprendizagem significativas” (FORMOSINHO, OLIVEIRA-FORMOSINHO, 2019, p. 17).

A imagem integral da criança também é reforçada, tendo em vista que não são enfatizados aspectos cognitivos, em detrimento dos emocionais, sensíveis e expressivos, isto é, são observadas todas as dimensões envolvidas na constituição do sujeito-criança (ROCHA, 2001). Diante disso, Carvalho e Fochi (2017, p. 27) destacam que o documento desafia a pensar propostas que "articulem as experiências e os saberes das crianças com os conhecimentos socialmente produzidos, diferenciando [...] o currículo da educação infantil de uma visão propedêutica de escolarizaçáo precoce das crianças para as etapas da educação básica”. Assim, mesmo que a Educação Infantil seja uma etapa da Educação Básica e articulada com esta,

3 Salienta-se que a autores como Dahlberg, Moss e Pence (2019) entendem as pedagogias decorrentes de estudos psicológicos, por entenderem que estas são resultado de uma imagem científica da criança e, como tal, tendem a pensar em uma perspetiva universalizante. 
buscando garantir a continuidade e a integração das aprendizagens (BRASIL, 2018), é preciso reconhecê-la com um caráter autotélico.

A Base Nacional Comum Curricular, documento de caráter normativo, reitera essas pressuposiçôes ao enfatizar que a Educação Infantil tem como objetivo "[...] ampliar o universo de experiências, conhecimentos e habilidades dessas crianças, diversificando e consolidando novas aprendizagens [...]" (BRASIL, 2018, p. 36). O mesmo documento salienta, em conformidade com o artigo $9^{\circ}$ da Diretrizes Curriculares Nacionais da Educação Infantil, que as práticas pedagógicas devem ser organizadas em torno dos eixos estruturantes das brincadeiras e das interaçôes. Essa definição, bem como os direitos de aprendizagem apresentados, reforçam a imagem de uma infância integral que aprende e se constitui de uma forma muito distinta do que preconizado pelas pedagogias que enfatizavam o treino, a instrução e a repetiçáo mecânica de atividades.

Dado esse contexto inicial, destacamos que, em nossa acepção, a definição de investigação vai ao encontro das proposiçôes da Pedagogia da Infância e dos pressupostos estabelecidos e descritos anteriormente. Para tanto, a Investigação, na Educação Infantil, assume um caráter distinto das práticas de Educar pela Pesquisa e do Ensino por Investigação, apresentando uma ênfase processual e abarcando, sem hierarquias axiológicas, as diferentes dimensôes do sujeito-criança e as cem linguagens das crianças (MALAGUZZI, 2016). Assim, assumimos a investigação como uma materialização da curiosidade humana (LIVIO, 2018), uma atitude cotidiana (SILVA, 2011) e que apresenta um caráter ético, político e estético (HOYUELOS, 2020).

A curiosidade epistemológica, conforme Livio (2018), é o que diferencia o ser humano dos demais seres vivos, sendo esta habilidade que permitiu à espécie humana desenvolver-se como tal:

[...] a curiosidade [epistemológica] é um processo mental de decisão cujo objetivo é maximizar o aprendizado. Para alcançar esse objetivo, são atribuídos valores a alternativas concorrentes com base no que se percebe como seu potencial para fornecer respostas a perguntas que intrigam o indivíduo. Assim, em essência, a curiosidade na verdade é um mecanismo de descoberta (LIVIO, 2018, p. 125).

Se pensarmos em bebês e crianças bem pequenas, a resposta à curiosidade, inata ao indivíduo, será a ação exploratória sobre o mundo, envolvendo seus múltiplos sentidos. Assim, mesmo desprovida da linguagem oral, a criança pequena desenvolve um conjunto de aprendizagens e suposiçōes sobre o mundo que a cerca. $\mathrm{O}$ aparecimento da oralidade e da comunicação oral com os adultos náo substituirá essa ação exploratória, mas sim irá complementá-la. Entendemos que essa exploração pode ser compreendida como uma forma de investigação, pois em ambos casos irá resultar na construção da aprendizagem ou na complexificação do conhecimento.

Silva (2011), ao tratar da investigação em uma perspectiva do Planejamento na Abordagem Emergente, afirma que ela pode ser pensada como uma atitude 
cotidiana, desenvolvida por crianças e adultos. Nesse viés, a atitude investigativa pode ser entendida como um esforço para obter uma informação específica ou diversa. Novamente, pode-se perceber uma proximidade entre os conceitos de investigação e curiosidade, em que a atitude investigativa é uma resposta do indivíduo à curiosidade, seja ela perceptiva, epistemológica, específica ou diversa (BERLYNE, 1978). Assim, por exemplo, em uma pesquisa científica desenvolve-se uma investigação epistemológica com "[...] a ânsia genuína por novos conhecimentos" (LIVIO, 2018, p. 69), enquanto cotidianamente, as investigaçóes, geralmente, são menos intensas e voltadas "[...] ao desejo ou necessidade por informaçôes distintas [ou] provocada por estímulos surpreendentes, ambíguos e novos" (LÍVIO, 2018, p. 69).

Por fim, temos os princípios éticos, estéticos e políticos, que marcam a investigação na Educação Infantil. Para Hoyuelos (2020, p. 24), a ética está voltada ao reconhecimento da "criança como um sujeito de direitos históricos e culturais", isto é, sua realização contempla a participação das crianças na organização da proposta curricular e o desenvolvimento de uma escuta responsiva por parte dos adultos que as acompanham. A dimensão política das práticas investigativas é decorrente do fato delas possibilitarem a solidariedade intelectual, uma aprendizagem relacional e a compreensão da participação como um valor institucional (HOYUELOS, 2020). Por fim, há os princípios estéticos da investigação, que se referem à possibilidade de ela ser uma forma de desenvolver contextos representativos e um microssistema afetivo e acolhedor (BRONFENBRENNER, 2011).

Frente ao exposto, definimos a investigação, no contexto da Educação Infantil, como toda "a ação empreendida pelo indivíduo com intuito de compreender o meio em que está inserido, é uma atitude que se manifesta na mais tenra idade" (LORENZON, 2021, p. 42). Tendo em vista que tais açóes, em sua natureza, são distintas, trabalhamos com três tipologias de investigação que podem ocorrer no espaço escolar: as cotidianas, as exploratórias e as projetadas. Essas categorias servirão para realização da análise dos dados do estudo e, em decorrência disso, serão posteriormente apresentadas e discutidas.

\section{Desenho da Investigaçáo}

A pesquisa desenvolvida possui um caráter qualitativo. A opção por essa abordagem dá-se em razão do próprio objetivo de estudo, o qual, segundo nosso entendimento, requer uma análise descritiva, a fim de desvelar as nuances envolvidas na interface existente entre a investigação e os demais princípios do planejamento pedagógico. Tendo em vista que há um número expressivo de tipos de pesquisa qualitativa, optamos pelo desenvolvimento de uma Investigação Pedagógica (RINALDI, 2016).

A Investigação Pedagógica, para Rinaldi (2016), é uma pesquisa empreendida pelo docente sobre as suas práticas pedagógicas com intuito de compreender acontecimentos que vivencia, observa e registra. O primeiro resultado da Investigaçáo Pedagógica, conforme a autora, é o desenvolvimento profissional 
e pessoal decorrentes das novas compreensóes produzidas sobre os fenômenos. Hoyuelos e Riera (2019) corroboram com essa perspectiva, afirmando que os contínuos processos de observação, registro e reflexão da prática pedagógica possibilitam aos docentes ferramentas que permitam intervençôes mais adequadas. Assim, os resultados obtidos em uma Investigação Pedagógica retroalimentam as práticas pedagógicas, qualificando-as.

O instrumento utilizado para a produção do corpus da Investigação Pedagógica foi a documentaçáo pedagógica produzida por um dos autores, junto a uma turma de Educaçáo Infantil, no período de 2019 a 2021. Assim, a seleçâo dos episódios que serão apresentados no decorrer do estudo segue um critério de conveniência, isto é, foram selecionados episódios que contêm situações significativas aos objetivos do presente estudo. Cabe salientar que as situaçôes apresentadas atendem a dois pressupostos: particularidades e extensibilidade.

A particularidade diz respeito à impossibilidade de reaplicar uma prática pedagógica de tal modo que ela ocorreu, pois sobre ela incidem variáveis, tais como: os saberes docentes, as infâncias existentes na instituição de ensino, além dos fatores do microssistema e condicionantes do exossistema (BRONFENBRENNER, 2011; HOYUELOS, 2020). No entanto, tais práticas ocorridas em um contexto específico apresentam um princípio de extensibilidade, isto é, os saberes decorrentes dela podem servir de inspiraçáo ou elemento promotor de mudanças em outros contextos.

Os episódios, recortes das práticas pedagógicas, foram organizados em três categorias: as Investigaçóes Cotidianas, as Investigaçôes Exploratórias e as Investigaçóes Projetadas. Após a disposição dos episódios nesses agrupamentos, confrontamo-nos com marcos teóricos, a fim de "[...] dotar de sentido as observaçóes recolhidas e a construir um alfabeto observacional que facilite a análise" (HOYUELOS, RIERA, 2019, p. 99). A partir disso, construímos esquemas conceituais que permitem a extensibilidade das práticas relatadas.

A análise do material aproximou-se da abordagem molar, proposta por Sanambria (2002) e Hoyuelos e Riera (2019). Para os autores, uma análise molar é um esforço empreendido pelos pesquisadores para compreender os fenômenos de modo processual, analisando as interaçôes com o entorno (HOYUELOS, RIERA, 2019). A fim de manter a integridade ética da pesquisa, foram atribuídos nomes fictícios às crianças participantes do estudo.

\section{As Investigaçóes no cotidiano da Educaçáo Infantil e as suas implicaçóes}

Nesta seçáo do artigo, apresentamos e analisamos episódios sobre diferentes modalidades de investigação que ocorrem no contexto da escola de Educação Infantil, buscando identificar a interface existente entre a investigação e os demais princípios do planejamento pedagógico. Tal como exposto anteriormente, abordaremos, respectivamente, as Investigaçóes Cotidianas, as Investigaçóes Exploratórias e as Investigaçóes Projetadas. 
As Investigaçóes Cotidianas são aquelas que as crianças realizam em decorrência de sua curiosidade perceptiva, em momentos rotineiros e de modo espontâneo, para solucionar um determinado problema. Essas investigaçóes, geralmente, não se estendem por longos períodos de tempo, isto é, são pontuais, mas podem voltar a ocorrer nos dias e semanas subsequentes. Para Carvalho e Fochi (2017, p. 25):

Existe, nas atividades cotidianas, a continuidade de determinadas situaçóes que, pela sua repetição, tanto nos asseguram criar intimidades e nos apropriarmos, como também nos dão terra firme para podermos vislumbrar o mundo que nos cerca. Ao mesmo tempo, são nelas que emergem acontecimentos imprevistos, abrindo-nos para alargar horizontes e afrontar o desconhecido.

É por meio desta aparente ambiguidade do cotidiano que a criança tem segurança emocional para avançar em novas experiências e exploraçóes e, consequentemente, construindo suas aprendizagens e hipóteses sobre as relaçóes e mundo físico que as envolve. No recorte abaixo, há um episódio em que a criança Daniel realiza uma dessas investigaçóes para solucionar um problema (alcançar a caixa de brinquedos):

Daniel é uma criança que está na turma B. Enquanto seus colegas estáo sentados no cháo explorando os livros, ele observa uma cesta de brinquedos que está sobre uma pilha de colchões. Ele olha para o adulto que acompanha a turma e em seguida aponta para a cesta. $\mathrm{O}$ adulto fala para ele brincar com livros, mas ele levanta e dirige-se a pilha de colchóes, ao aproximar-se, estende as mãos. Como ele náo alcança, começa a tentar balançar os colchóes e observa se a cesta se movimenta ou náo. A professora que acompanha a turma o chama dizendo que náo é hora de brincar com os brinquedos.

A partir do excerto, identifica-se que as Investigaçóes Cotidianas são uma resposta a um problema com que a criança se deparou e, por não ter a linguagem oral suficientemente desenvolvida para comunicar-se com o adulto, ela passa a adotar uma ação. A tentativa de balançar os colchóes e, concomitantemente, observar se a cesta se movia, serve como um indicador de uma açáo planejada. Os movimentos empreendidos por Daniel não se caracterizam como um exercício, mas sim como uma ação, possivelmente baseada em uma experiência ou uma hipótese. Assim, a experiência investigativa foi acompanhada de processos cognitivos de processamento e criaçáo de novas hipóteses.

Outro aspecto que pode ser observado é que as Investigações Cotidianas ocorrem, geralmente, de modo individual, isto é, percebemos a criança em um profundo envolvimento consigo mesma. No entanto, registramos alguns episódios em que as crianças interagem entre si ou, ao observarem seus colegas, aperfeiçoam seus movimentos e habilidades. Um desses casos pode ser observado no excerto abaixo:

Depois do momento de brincar livre, as massas de modelar são distribuídas para as crianças. Em seguida, o professor distribui formas de plástico e tesouras, sugerindo que as crianças as utilizem para realizar recortes. A Criança Joel (4 anos), que ainda não manuseava corretamente a utilizava para realizar punção, 
fazendo furos em sua massa. Enquanto isso, o colega que estava próximo a ele, faz cobrinhas de massa de modelar e as cortá-las com a tesoura. A criança Joel começa a fazer o mesmo que seu colega e passa a manusear a tesoura com as duas mãos.

Nesse viés, observamos que momentos em que as crianças apenas estáo juntas, sem uma comunicação efetiva, também são profícuos para o aprender sem que haja o treino e o direcionamento do adulto. Corroboramos com Malaguzzi (2016) quando afirma que aprendizagem e ensino não podem ser sinônimos, tendo em vista que muitas das aprendizagens das crianças decorrem de exploraçóes e das interaçôes delas com os recursos ofertados pelos docentes. Assim, a partir das situaçôes observadas no decorrer das práticas pedagógicas, infere-se que, mais do que uma prática autotélica, as situaçôes de Investigaçôes Cotidianas são momentos importantes para a aprendizagem das crianças, sem a necessidade de adotar abordagem transmissiva de ensino.

Um outro aspecto que pode ser contextualizado como uma forma de Investigação Cotidiana são as mordidas das crianças em seus pares. Entendemos que essas açôes não decorrem de algo patológico, mas sim do interesse da criança em explorar o seu meio. No entanto, é preciso relembrar que as investigaçóes, mesmo espontâneas, devem passar pelo crivo dos princípios éticos, dentre os quais está a solidariedade e o bem comum. Assim, a curiosidade humana não pode se sobrepor à ética do cuidado e da responsividade com o outro.

No cotidiano da Educação Infantil, identificamos também as Investigaçóes Exploratórias que são decorrentes das interaçóes entre as crianças e os materiais. Mesmo que elas possam ocorrer de modo espontâneo e cotidiano, classificamos tais interaçóes em uma categoria distinta, pois muitas vezes elas podem ser potencializadas por meio de intervençóes planejadas por parte do docente. $\mathrm{Na}$ Imagem 1, apresentamos o Recanto dos Materiais, espaço organizado em uma escola de Educação Infantil, com intuito de possibilitar as exploraçóes sensoriais e construtivas das crianças. 
Imagem 1: Espaços e Materiais em uma Escola de Educação Infantil

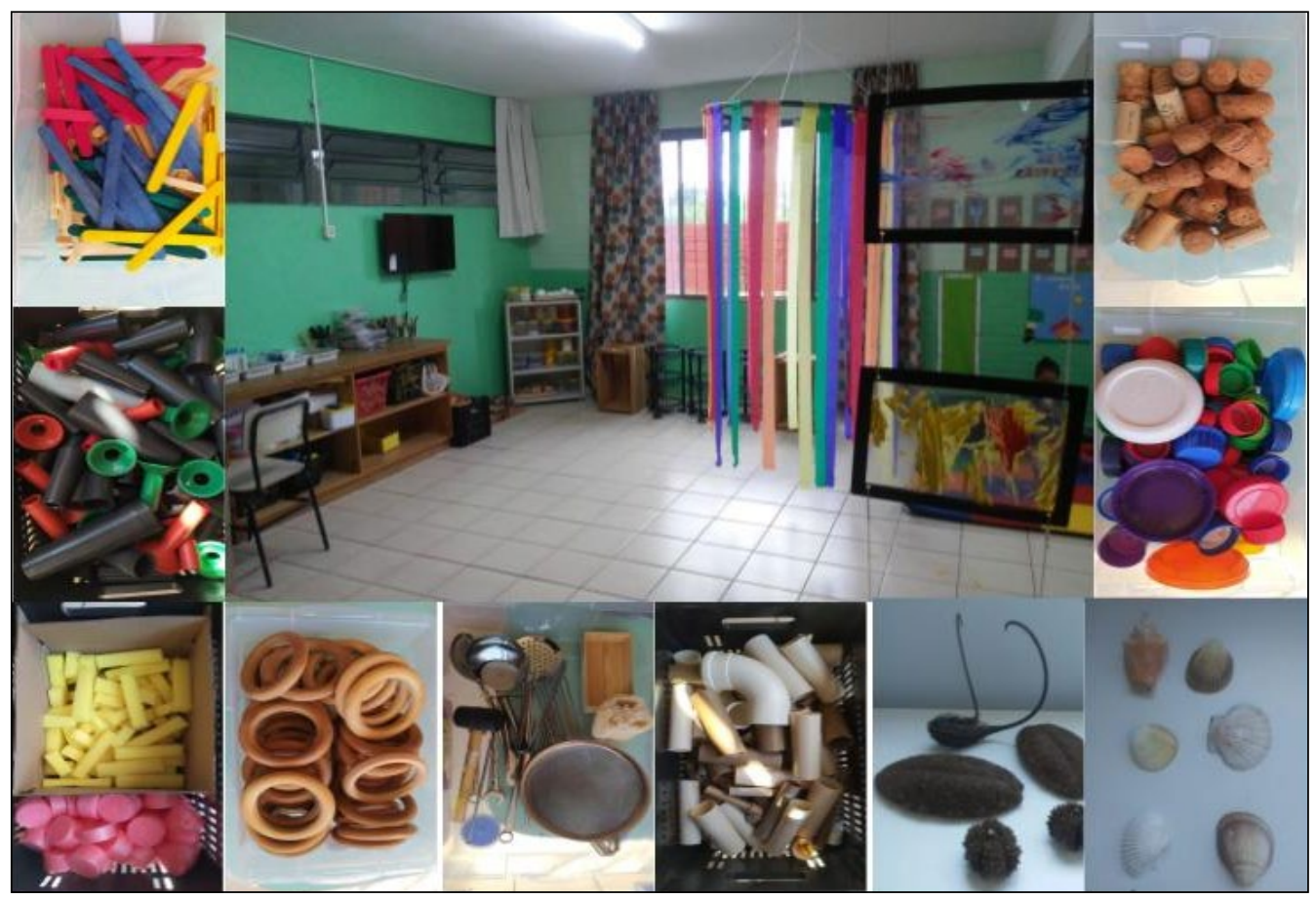

Fonte: Autores

Como pode ser observado na Imagem 1, os materiais que constituem o recanto são diversos e selecionados de modo intencional devido às suas qualidades sensoriais, permitindo novas experiências às crianças no que diz respeito a esse aspecto. Contemporaneamente, autores, entre os quais estáo Louv (2016) e Friedmann (2020), destacam que as crianças convivem majoritariamente em espaços artificiais e assépticos, que as privam de experiências multissensoriais constitutivas da criança. Assim, as mudanças dos espaços urbanos, a consolidaçáo de um paradigma funcional-higienista e até mesmo a mudança arquitetônica na organização das habitaçóes - onde, cada vez menos, as crianças possuem espaço para explorar os elementos naturais - levam a uma necessidade da escolarizaçáo das experiências sensíveis.

Além disso, as Investigações Exploratórias são oportunidades para as crianças construírem aprendizagens acerca do funcionamento do mundo físico. Um desses episódios pode ser encontrado no Diário de Aula do mês de fevereiro de 2021, no qual há um relato de duas crianças que exploram tubos de borracha:

A Criança Enrico e a Criança Sara estavam explorando os materiais dispostos no Recanto dos Materiais. Elas pegaram um longo tubo de borracha e postaram-se uma em cada ponta. Enquanto uma usava-o como microfone, a outra colocava em seu ouvido para ouvir e colega, sendo que em seguida invertem os papéis. Depois de um tempo falando pelo tubo e ouvindo a 
colega, a Criança Enrico sugere que a Criança Sara esconda-se e tente falar pelo tubo para ver se mesmo sem vê-la, ela conseguiria ouvi-la (Diário de Aula, fevereiro de 2021).

Essa aprendizagem, que decorre da exploração e não do ensino direto, assemelha-se ao que Resnick (2020) designa de aprendizagem criativa, isto é, uma aprendizagem que envolve o imaginar, o criar, o brincar, o compartilhar e o refletir. $\mathrm{O}$ autor aponta ainda a relação existente entre o ato exploratório e o desenvolvimento de processos cognitivos, afirmando que ambos estão associados, pois "[...] à medida que as crianças constroem coisas no mundo, elas constroem novas ideias em suas mentes, o que as incentiva a construir novas coisas no mundo e assim por diante, em uma espiral infinita de aprendizagem" (RESNICK, 2020, p. 36). Staccioli (2013, p. 77) corrobora com essa perspectiva ao afirmar que as exploraçôes sensoriais e autônomas das crianças "(...) acrescentam a elas um nível de consciência e raciocínio mais elevado". Frente ao exposto, percebemos que as Investigaçóes Exploratórias desencadeiam processos cognitivos nas crianças e, ao mesmo tempo, são retroalimentadas por elas.

Em outro episódio, registrado em fevereiro de 2021, um grupo de crianças já familiarizados com os materiais, buscou combinar materiais esféricos e os tubos de borracha de diferentes diâmetros, como pode ser observado no excerto abaixo:

Um grupo de crianças pegou os tubos de PVC e borracha que estavam dispostos no canto dos materiais e os materiais esféricos (bolas de isopor e de vidro). O grupo se reuniu e um dos integrantes tentava inserir as esferas pelo tubo. Uma outra criança esperava na outra extremidade para observar se o material iria sair ou ficaria trancado. Enquanto isso, os demais integrantes do grupo manuseavam os tubos mais longos e flexíveis testando se os movimentos que eles faziam interferiam no tempo que as esferas demoravam para passar (Diário de Aula, Fevereiro de 2021).

Observamos ainda que as Investigaçóes Exploratórias, inicialmente estão voltadas para o desenvolvimento de habilidades motoras, em que as crianças manipulam, coordenam e combinam os diferentes materiais. No entanto, com o passar do tempo, as crianças começam a familiarizar-se com os recursos e compreendendo as suas possibilidades, suas propriedades físicas e testando novas e inéditas possibilidades de combinação.

Mesmo que, em nosso entendimento, todos os materiais sejam importantes para as Investigaçóes Exploratórias, é necessário que a seleção dos recursos apresentados seja criteriosamente avaliada por parte do educador. Primeiramente, é necessário escolher recursos que não representem riscos à integridade física e ao bem estar da criança. Soma-se a isso o fato de cada material, conforme Hoyuelos (2020), ter uma linguagem própria, ou seja, precisam ser convidativos a algumas operaçóes. Assim, em nossas práticas pedagógicas, por exemplo, temos observado que esferas grandes e de diferentes materiais são convidativas a jogos de exercício e uma movimentação mais ampla. Dessa forma, elas não são adequadas a espaços com restritas possibilidades de movimentação. Cada material, ao ser selecionado, demanda um plano de ação em que o docente hipotetiza os usos que as crianças 
farão dele e quais as possibilidades de combiná-lo com o que tenha disponível em sala de aula.

A última categoria aborda as Investigaçôes Projetadas, que são decorrentes de uma adaptação da proposta de Espiral Investigativa (LORENZON, 2018, 2021). Uma Investigaçáo Projetada emerge do cotidiano, surgindo tanto dos interesses das crianças, como da necessidade de trabalhar um tópico específico. Geralmente, esse tipo de investigação compreende um grande grupo de crianças que se envolve no estudo de um tema específico, realizando atividades de busca de informaçóes, sintetização de dados, realização de experimentos e saídas de estudo e comunicação dos achados.

Ao avaliar a documentação pedagógica produzida no período entre 2019 e 2021, selecionamos dois projetos representativos desta categoria: "Investigação sobre a Vida dos Dinossauros" "Investigação 'Por que lavar as mãos?". A primeira investigação ocorreu a partir do interesse das crianças acerca dos animais pré-históricos, que eram latentes nos momentos de brincar livre e nos momentos de roda. Mesmo que as crianças possuíam familiaridade com o tema, optamos por trabalhá-lo, visto que, conforme Katz (2016), as investigaçóes de temas conhecidos oferecem às crianças oportunidades de serem protagonistas na planificação do trabalho pedagógico, trazendo informaçôes ou até mesmo propondo situaçóes de aprendizagem. Já a investigaçáo sobre o "Por que lavar as mãos?" foi proposta pelo docente e surgiu de questionamentos das crianças sobre a necessidade de lavar as mãos com frequência. Assim, o projeto decorreu da necessidade de garantir o bem-estar das crianças, mas de forma condizente com o desenvolvimento da sua autonomia moral.

No caso das Investigaçôes Projetadas, a primeira etapa consiste em explicitar o que as crianças sabem acerca do tema para, a partir disso, elaborar os questionamentos de investigações. A proposição dessas situaçóes de aprendizagem decorre do entendimento de que as perguntas são indicadoras de lacunas no conhecimento (LIVIO, 2018). Dessa forma, reconhecer o que se conhece sobre determinado tema é condição necessária para a elaboração de perguntas generativas (HOYUELOS, RIERA, 2019) e capazes de desencadear boas investigaçôes.

A partir da elaboração dos questionamentos, formularam-se algumas hipóteses, isto é, suposiçóes e respostas provisórias às questóes orientadoras da investigação. Como as crianças participantes ainda não dominavam a linguagem escrita, optou-se por elas desenharem as hipóteses e, posteriormente, apresentarem aos colegas as suas suposiçóes. $\mathrm{Na}$ Imagem 2, podem ser observadas hipóteses das crianças ao questionamento "Como é um microrganismo?": 
Imagem 2: Hipótese sobre a forma dos microrganismos

\section{PROJETO MICRO-ORGANISMOS}

Nesta semana, iniciamos um projeto sobre os Micro-organismos. Na segunda-feira, ouvimos histórias e assistimos alguns vídeos sobre esses seres microscópios. Hoje, desenharemos a nossa hipótese de como são esses pequenos seres vivos.

Data: 03 de março de 2020

Fonte: Produção de Criança Isadora (4 anos)

A partir das hipóteses das crianças, inicia-se um processo de buscar informaçôes que deem sustentação a estas suposiçóes iniciais. No caso da Investigação "Por que lavar as mãos?", foi realizado o cultivo de microrganismos. Para isso, coletou-se material das mãos das crianças antes e depois de lavarem as mãos. Essa coleta foi inoculada em um meio de cultivo previamente preparado pelo professor. Com o passar do tempo, as crianças puderam observar e comparar a diferença entre ambas as amostras. No entanto, há um conjunto amplo de situaçóes de aprendizagem que podem ser realizadas com intuito de responder aos questionamentos das crianças, tais como visitas a espaços não formais de ensino, como Jardim Botânico e Museus de Ciências. Além disso, em nossas práticas pedagógicas, temos observado que 
analisar de infográficos, ler de forma compartilhada e assistir a vídeos-minutos e a breves documentários têm colaborado significativamente para as investigaçóes desenvolvidas. Diante disso, é necessário que os professores também explorem diferentes recursos, a fim de observar se estão de acordo com as necessidades das crianças.

Imagem 3: Visita ao Museu

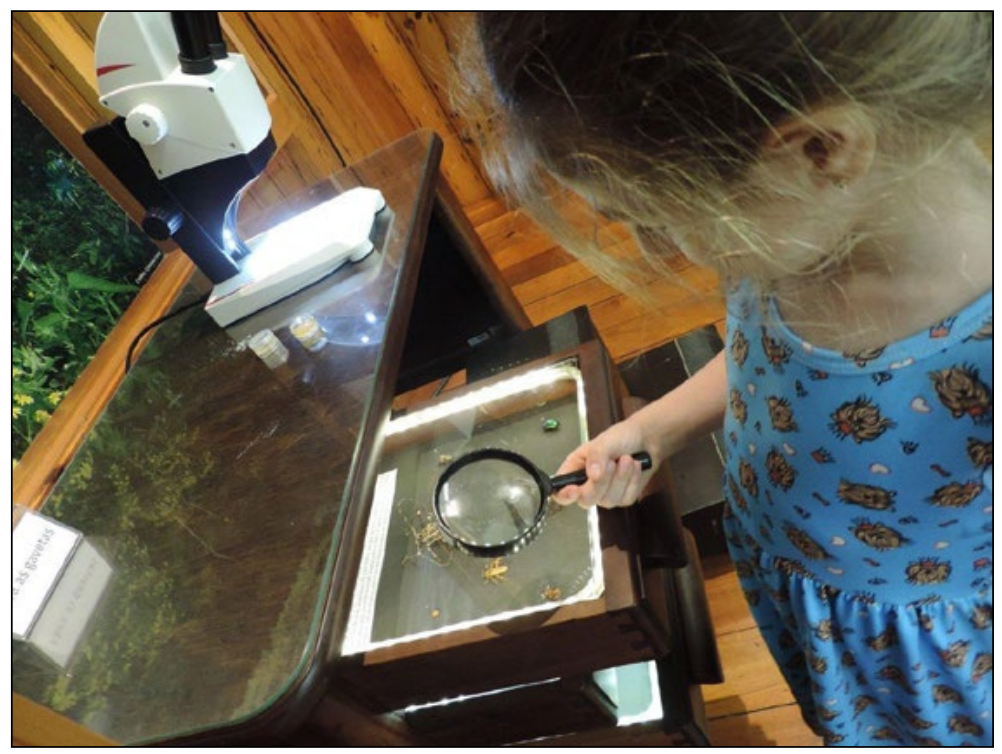

Fonte: Acervo do Autor

Por fim, os resultados das Investigações Planejadas são comunicados para os integrantes da comunidade escolar, seja por meio de exposiçóes, de documentação pedagógica ou produçóes audiovisuais. Essa etapa final desempenha um papel importante, pois, além de dar visibilidade às aprendizagens das crianças, valoriza os seus processos investigativos. Diferentemente do que as Investigaçóes Cotidianas e Exploratórias, as Investigaçóes Projetadas deixam evidentes processos cognitivos empreendidos pelas crianças, tais como as comparaçóes, análises e inferências, permitindo assim mais possibilidades de documentá-las.

\section{Consideraçóes Finais}

O objetivo deste artigo consistiu em apresentar recortes de práticas investigativas realizadas junto a crianças da Educação Infantil, analisando a interface existente entre a investigaçáo e os demais princípios do planejamento pedagógico. As investigaçóes, categorizadas no estudo como Cotidianas, Exploratórias ou Projetadas, foram apresentadas no decorrer do estudo como uma possibilidade de trabalho condizente com a Pedagogia das Infâncias. Mesmo que as três categorias apresentadas guardem diferenças entre si, é importante perceber que todas 
convergem ao indicar a necessidade do protagonismo das crianças, a importância de uma pedagogia orgânica e sistêmica e a aposta em uma aprendizagem relacional. Em todas as práticas investigativas, percebemos ainda a presença da curiosidade, da expressividade e da construtividade.

Ao longo do período analisado (2019-2021), percebemos que as Investigaçôes Cotidianas, mesmo estando presentes em todas as faixas etárias, são mais frequentes em crianças pequenas. Entendemos que, em partes, isso decorre do fato de a linguagem oral ainda não estar plenamente desenvolvida. Por isso, essa forma de investigação é uma maneira de as crianças construírem o conhecimento de mundo e também desenvolverem múltiplas habilidades. As Investigações Cotidianas demandam, sobretudo, um respeito ao tempo da criança.

As Investigaçóes Exploratórias também podem ocorrer sem demandar recursos e materiais específicos. No entanto, percebendo que ela é potencialmente significativa para o desenvolvimento das crianças, optamos por selecionar materiais multissensoriais e que carregam mensagens de desafio para as crianças. Como afirmado no decorrer do estudo, as interaçóes entre as crianças e os materiais desencadearão processos cognitivos, resultando em aprendizagens cada vez mais complexas sobre as propriedades dos materiais e do mundo físico. Nesse caso, cabe ao docente selecionar e refletir sobre os materiais ofertados, buscando ampliar as experiências sensoriais das crianças e, ao mesmo tempo, garantir seu bem-estar físico.

Por fim, a terceira categoria trata de Investigaçóes Projetadas, isto é, investigaçóes que são oriundas dos interesses e das necessidades das crianças e resultam em projetos sobre um determinado tópico. Esse terceiro tipo de investigaçáo apresenta um caráter mais formal e, muitas vezes, aborda explicitamente termos e conceitos científicos. Nessas situaçóes, as crianças trabalham de modo cooperativo, fazendo negociações e dialogando sobre suas ideias e as construçôes que irão realizar.

Mesmo adotando diferentes adjetivos para caracterizar as investigaçóes ocorridas no contexto da escola de Educaçáo Infantil, entendemos que o ato de investigar requer o protagonismo das crianças e, consequentemente, o reconhecimento que as aprendizagens individuais são emergentes da ação da criança sobre o mundo e os materiais, mas também das suas interaçóes com os seus pares. Além disso, é necessário um respeito ao tempo da criança, evitando compreender essa etapa do ensino como um período preparatório para os anos vindouros e resistindo aos paradigmas escolarizantes da infância.

Mesmo que as investigaçóes possam ser cotidianas, não demandando recursos específicos, entendemos que a existência de espaços que sejam propulsores de novas aprendizagens pode proporcionar experiências mais significativas para as crianças. $\mathrm{O}$ conceito de espaço remete a pensar, tanto o ambiente físico, que contempla a organização arquitetônica e a disposição de objetos, como um espaço afetivo que garanta o direito das crianças a perguntarem e que seus questionamentos sejam levados a sério pelos adultos. Por fim, entendemos que o desenvolvimento de práticas investigativas no contexto da Educação Infantil, por promoverem a escuta 
das crianças e fomentar as suas experiências sensoriais, abre a possibilidade para criaçôes inéditas. Nesse viés, a investigação aproxima-se de conceitos como a construtividade, a inventividade e a criatividade.

\section{Referências}

BRASIL. Base Nacional Comum Curricular. 2018. Disponível em: http:// basenacionalcomum.mec.gov.br/ Acesso: 24 de Março de 2021.

BRASIL. Diretrizes Curriculares Nacionais para a Educaçáo Infantil. Disponível em: https://www.legisweb.com.br/legislacao/?id=112015 Acesso: 06 de Abril de 2021.

BERLYNE, D. E., Curiosity and learning. Motivation and Emotion. vol. 2, 1978. p. 97-175.

BRONFENBRENNER, U. Bioecologia do desenvolvimento humano: tornando os seres humanos mais humanos. Porto Alegre: Artmed, 2011.

CARVALHO, R. S. de; FOCHI, P. S. Pedagogia do cotidiano: reivindicaçôes do currículo para a formação de professores. Em Aberto. v. 30, n. 100. Brasília: set/dez. 2017. p. 2342.

. "O muro serve para separar os grandes dos pequenos": Narrativas para pensar uma pedagogia do cotidiano na Educaçâo Infantil. Textura. v. 18. p. 36.

COHN, C, Antropologia da Criança. Rio de Janeiro: Editora Zahar, 2005.

CORSARO, W. A. Sociologia da Infância. Porto Alegre: Artmed, 2011.

DAHLBERG, G.; MOSS, P.; PENCE, A. Qualidade na Educaçáo da Primeira Infância: perspectivas pós-modernas. Porto Alegre: Penso, 2019.

FRIEDMANN, A. A vez e a voz das crianças: Escutas antropológicas e poéticas das infâncias. São Paulo: Panda Books, 2020.

HOYUELOS, A. A Estética no pensamento e na obra de Loris Malaguzzi. São Paulo: Phorte Editora, 2020.

HOYUELOS, A.; RIERA, M. A. Complexidade e Relaçóes na Educação Infantil. São Paulo: Phorte Editora, 2020.

KATZ, L. O que podemos aprender com Reggio Emilia? In.: EDWARDS, C.; GANDINI, L.;FORMAN, G, (org). As Cem Linguagens da Criança: A abordagem de Reggio Emilia na educação da primeira infância. Porto Alegre: Editora Penso, 2016. p. $37-56$.

LIVIO, M. Por quê? O que nos torna curiosos. Rio de Janeiro: Record, 2018. 
LORENZON, M. A espiral investigativa como uma estratégia de desenvolvimento da Alfabetização Científica nos Anos Iniciais do Ensino Fundamental. Dissertação (Mestrado) - Curso de Ensino, Universidade do Vale do Taquari - Univates, Lajeado: 2018.

- A investigação na escola de educação básica: relatos, desafios e possibilidades a partir de uma prática nos Anos Iniciais do Ensino Fundamental. In.: SILVA, J. S. (et al). Práticas de Ensino Investigativas: Da Educação Infantil à Pós Graduação. Lajeado: Editora Univates, 2021.

LOUV, R. A última criança na natureza: resgatando nossas crianças do transtorno do deficit de natureza. São Paulo: Aquariana, 2016.

MALAGUZZI, L. De jeito nenhum. As cem estão lá. EDWARDS, C.; GANDINI, L.; FORMAN, G. As Cem Linguagens da Criança: A experiência de Reggio Emilia em transformação. Porto Alegre: Editora Penso, 2016. p. 20-23.

OLIVEIRA-FORMOSINHO, J.; FORMOSINHO, J. Pedagogia em participação: em busca de uma práxis holística. In.: OLIVEIRA-FORMOSINHO, J.; PASCAL, J. Documentação pedagógica e avaliação na Educaçáo Infantil: um caminho para a transformação. Porto Alegre: Penso, 2020. p. 26-58.

REDIN, M. M.; FOCHI, P. S. Explorar e Interagir com o mundo: os materiais na Educação Infantil. In.: REDIN, M. M. Infância e Educação Infantil II: Linguagens, São Leopoldo: Editora Unisinos, 2014. p. 51-64.

RESNICK, M. Jardim de Infância para a vida toda: por uma aprendizagem criativa, mão na massa e relevante para todos. Porto Alegre: Penso, 2020.

RINALDI, C. Diálogos com Reggio Emilia: Escutar, investigar e aprender. São Paulo: Paz e Terra, 2016.

ROCHA, E. A. C. A pedagogia e a Educação Infantil. Revista Brasileira de Educaçáo. n. 16. Jan/Fev/Mar/Abr. 2001. p. 27-34.

ROCHA, E. A. C.; LESSA, J. S.; BUSS-SIMÃO, M. Pedagogia da Infância: interlocuçóes disciplinares na pesquisa em Educação. Da Investigaçáo às Práticas. v. 6, n. 1. 2016. p. 31-49.

SANABRIA, F. Análisis molar y molecular: dos visiones de la conducta. Universidad Psychol. Bogotá (Colômbia). v. 1. n. 2. Júl/Dez., 2002. p. 27-33.

STACCIOLI, G. Diário do acolhimento na escola da infância. Campinas: Autores Associados, 2013.

SILVA, J. S. da. O Planejamento no Enfoque Emergente: Uma experiência no $1^{\circ}$ Ano do Ensino Fundamental de Nove Anos. Tese (doutorado) - Universidade Federal do Rio Grande do Sul, Faculdade de Educação, Programa de Pós-Graduação em Educação, Porto Alegre: 2011. 